\title{
NON-LINEAR KINEMATIC ANALYSIS OF MASONRY WALLS OUT- OF-PLANE LOADED. THE COMPARATIVE ROLE OF FRICTION BETWEEN INTERLOCKED WALLS
}

\author{
Claudia Casapulla ${ }^{1}$, Luca U. Argiento ${ }^{1}$ \\ ${ }^{1}$ University of Napoli "Federico II" \\ Department of Structures for Engineering and Architecture, Napoli, Italy \\ \{casacla,lucaumberto.argiento\}@unina.it
}

Keywords: Dry Masonry Structures, Limit Analysis, Frictional Resistances, Pushover Analysis, Yielding of Tie-Rods, Masonry Vaults.

\begin{abstract}
In this paper the limit analysis of a simple out-of-plane failure mechanism of a laterally weakly connected masonry wall involving frictional resistances is developed according to the displacement-based approach. The pushover analysis is made considering geometric nonlinearity, i.e. by evaluating the static multiplier for varied kinematic configurations, as a function of the displacement of a control point. The effect of the interlocking between the front wall and the sidewalls gradually decreases after a certain displacement, due to the progressive detachment of the front wall and the variation of the frictional resistances can be represented by a non-linear function of the decreasing number of involved rows. The stabilizing role of friction between interlocked walls is compared to another system of strength in masonry buildings, i.e. the effect of tie-rods, with and without the detrimental effect of the static thrust of masonry vaults. The sensitivity of the load multiplier to these strength parameters is investigated with reference to different combinations of loading conditions. Comparative results and pushover curves are developed to evaluate the displacement capacities for each case analyzed.
\end{abstract}




\section{INTRODUCTION}

In masonry buildings without a box-type behavior and subjected to seismic loadings, inplane and out-of-plane failure mechanisms can take place where frictional resistances might play a predominant role. The analysis of the local failure modes is particularly recommended by the multi-level approach of the Italian Guidelines on Cultural Heritage [1].

There is a wealth of reference in the literature, concerned with the limit analysis of the local failure modes in existing masonry buildings, both with or without the contribution of frictional resistances [2-14]. These are mainly based on the static force-based approaches, leading, therefore, only to collapse load and collapse mechanism. On the other hand, out-of-plane modes can be analyzed by evaluating the evolution of motion over time; this consists in the integration of equation of motion, generally considering the energy dissipation of the rocking time history with a restitution coefficient that reduces rotation velocity after each impact. Interesting research has recently been developed in this field [15-23]. As an alternative, some displacement-based approaches were recently presented to investigate overturning that occurs under dynamic actions [24, 25]. However, the role of friction along the complete cycle of evolution of the mechanism has not yet been explored appropriately in any proposed method.

In this framework, this paper presents the analysis of the variation of frictional resistances during the evolution of a simple out-of-plane mechanism, i.e. the overturning of a masonry front wall weakly connected to the sidewalls. The role of these forces is particularly highlighted in comparison with another system of strength in masonry buildings, i.e. the tie-rods, also considering the detrimental effect of the static thrust of masonry vaults. Other overloading combinations and connection systems are discussed in more detailed works [26-28].

The pushover analysis of the façade is herein performed according to the displacementbased approach built on an incremental limit analysis of rigid blocks proposed by Lagomarsino [29]. According to the displacement-based assessment philosophy, the pushover curves for different combinations of the various effects are then performed from the static multipliers. These are obtained by the application of the theorem of virtual works, considering kinematic varied configurations of the considered mechanism, in large displacements. Along this incremental kinematic analysis, the contribution of links is taken into account, till the ultimate equilibrium condition.

\section{THE THREE-WALL SYSTEM UNDER OUT-OF-PLANE LOADING}

Although the following developments can easily be extended to all types of local failure modes, this paper is only focused on the simple overturning mechanism of a façade wall weakly connected with two sidewalls in order to achieve the main goal of highlighting the comparative role of friction after the activation of the mechanism. Two connection configurations for walls (interlocking, tie-rods) and the presence of a masonry vault are considered, as represented in Fig. 1a). For the sake of simplicity, the two sidewalls, i.e. shear walls, are herein assumed to have the same thickness as the front wall and all are assumed to be single leaf walls arranged in a running bond pattern. Whatever texture in wall thickness would not add any further information about the role of friction against a more detailed modeling approach.

The crack pattern is precisely identified a priori, as characterized by two vertical cogged cracks along the corners, where frictional resistances can take place. This means that the rotation of the façade around its external bottom edge can be considered as a combination of rocking and sliding due to sliding motions involved along the two vertical cogged cracks. The two defined macro-blocks (the resting and moving parts of the system) have infinite compressive strength, no tension is transmitted across the cracks and the limit on the shear force at the micro-block interfaces along the cracks is governed by the cohesionless Coulomb's law. Earth- 
quake action is considered as horizontal forces proportional, through a load multiplier, to dead and live loads. According to kinematic limit analysis, the static multiplier is obtained by the application of theorem of virtual works, considering a virtual infinitesimal varied configuration for the evolution of the failure mode, as described in Section 3.

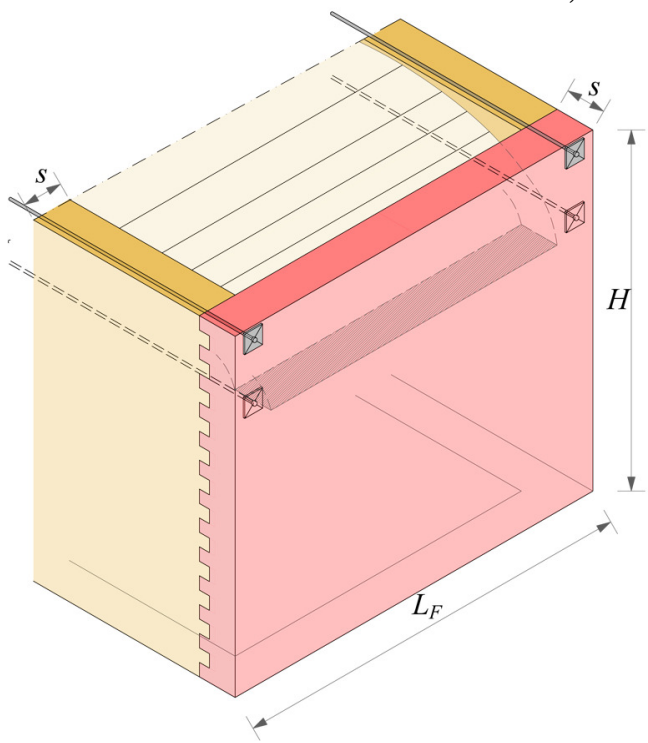

(a)

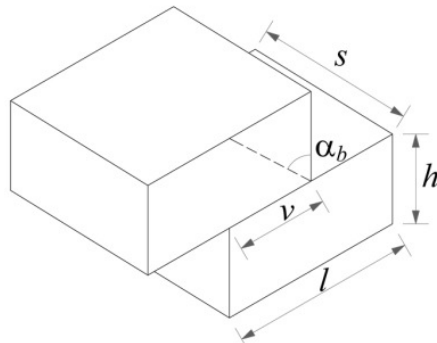

(b)

Figure 1: (a) Three-wall system and (b) Unit dimensions

\subsection{Cases investigated}

Different configurations of the three-wall system are analyzed in order to evaluate the improvement of the seismic performance due to the type of connections between walls (Fig. 1(a)). In Fig. 2 two cases with different combinations of loadings are represented. Case 1 considers the front wall without overloading, such as the realistic cases with floor beams parallel to the façade or with a masonry vault transferring loads to the sidewalls; Case 2 represents the presence of a vaulted masonry structure transferring static thrust together with some of its self-weight to the façade.

For the two cases, a first loading condition a) is considered taking into account the selfweight and inertia forces only - plus the static thrust for Case 2; the combinations b) and c) are instead referred to the contribution of the two systems of strength introduced above, in order to evaluate their impact on condition a). It is worth noting that different positions of the tie-rods are considered for the two cases. The wall slenderness and aspect ratio are assumed to be fixed parameters, i.e. $H / s=6.67$ and $H / L_{F}=0.8$, respectively (Fig. 1). All the applied forces and their application points are shown in Fig. 3 and reported in Table 1.

\begin{tabular}{c|c|c|c}
\hline Weights and static thrust & Horizontal level arm & Vertical level arm \\
\hline Self-weight & $P$ & $s_{P}=s / 2$ & $h_{P}=H / 2$ \\
Overload (vaulted structure) & $V_{V}$ & $s_{V}=3 / 4 s$ & - \\
Static thrust & $V_{H}$ & - & $h_{V}=5 / 7 \mathrm{H}$ \\
\hline \multicolumn{2}{c}{ Strength parameters } & Vertical level arm \\
\hline Yielding of the two tie-rods & $T$ & $h_{T}=H$ or $h_{V}$ \\
Total friction force between orthogonal walls & $F_{P}$ & $h_{F}=H / 3$
\end{tabular}

Table 1: Forces and level arms.

The resultant frictional resistance $F_{P}$ is expressed by the formulation [27, 28]: 


$$
F_{P}=\gamma \operatorname{shl} \frac{n(n+1)}{2} f
$$

where $s, h$ and $l$ are the unit dimensions (Fig. 1(b)), $\gamma$ is the specific weight of the material, $n$ is the number of rows and $f$ is the friction coefficient. This force is applied at $1 / 3$ of the height of the cracked parts from the bottom of the panels.

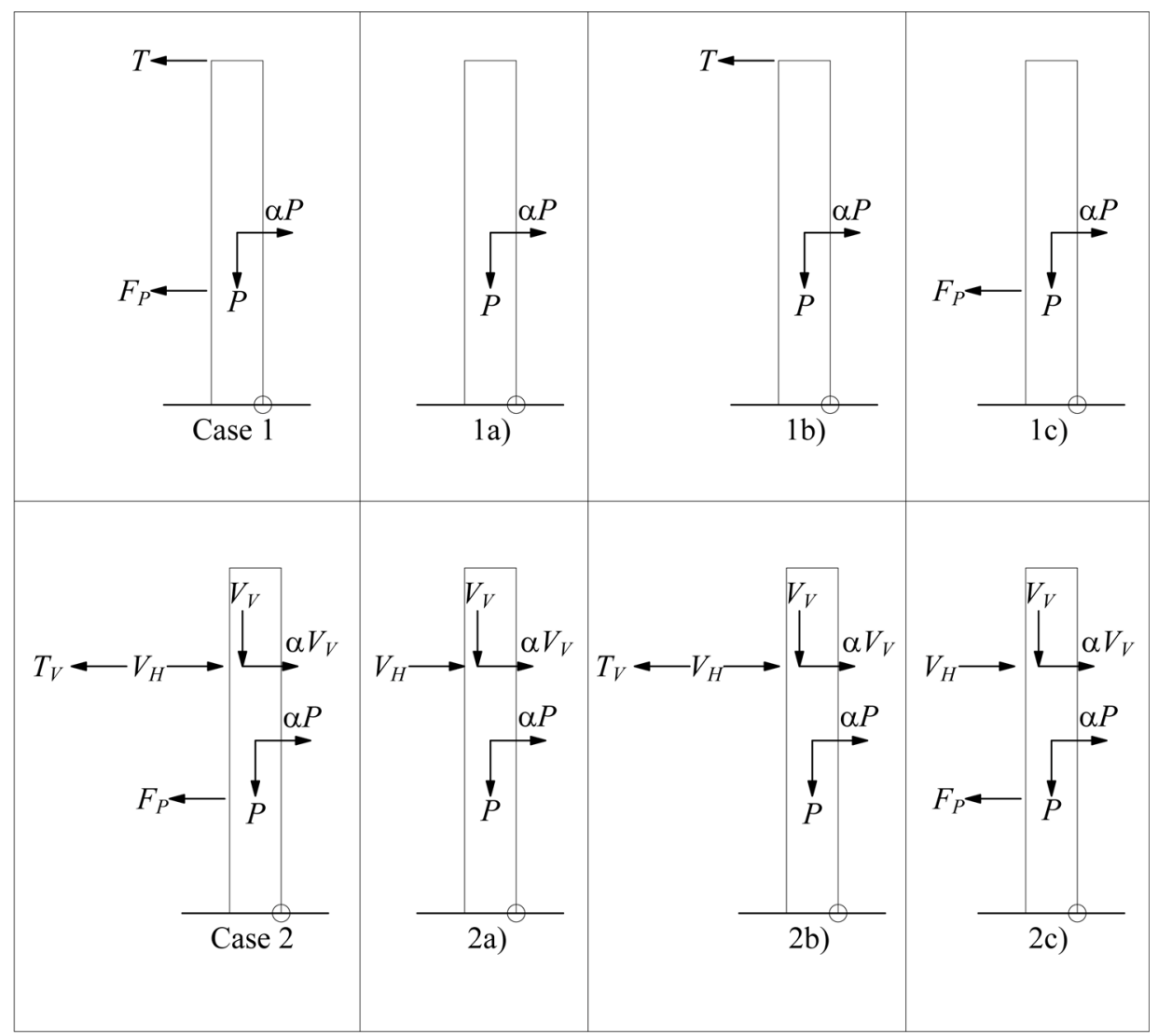

Figure 2: Two loading configurations for the façade and different combinations of the loading conditions.

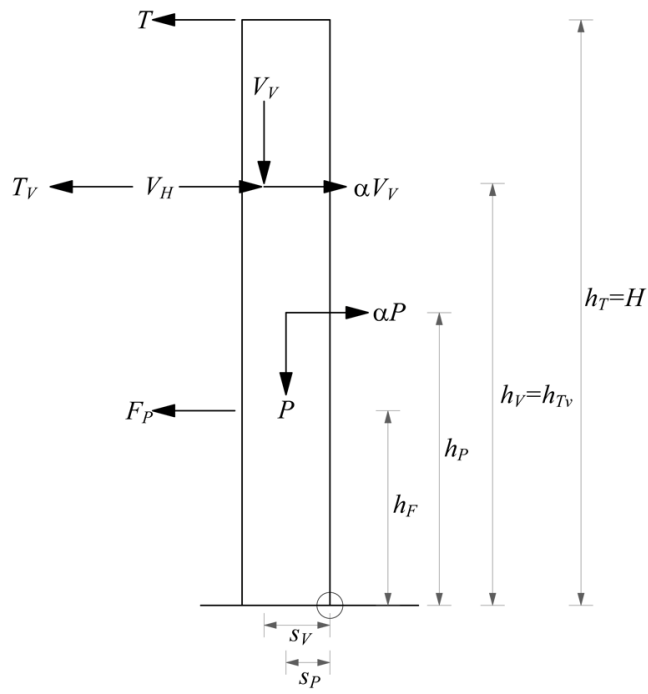

Figure 3: Forces and application points on the façade wall. 


\section{THE COMPARATIVE ROLE OF FRICTION AFTER THE HINGE FORMATION. PUSHOVER ANALYSIS}

In the following, the pushover analysis is carried out by evaluating the static multiplier for varied kinematic configurations, as a function of the displacement of the centre of gravity of the façade wall, assumed as the control point. In Fig. 4 the wall rotation of a generic positive value of the angle $\theta$ is shown together with the corresponding coordinates of the application point of the $j$-th applied load $W_{j}$. The virtual work done by this single load, considering a virtual infinitesimal varied configuration, can be expressed as:

$$
L_{W j}=\alpha W_{j} y_{j} \phi-W_{j} x_{j} \phi
$$

where $\phi$ is the virtual rotation and:

$$
x_{j}=R_{j} \cos \left(\gamma_{j}+\theta\right) ; \quad y_{j}=R_{j} \sin \left(\gamma_{j}+\theta\right) ; \quad \gamma_{j}=\tan ^{-1}\left(\frac{h_{j}}{s_{j}}\right)
$$

are the coordinates of the $j$-th application point and its position angle with respect to the hinge.

By considering all the applied loads and having simplified out the virtual parameter of distortion $\phi$, the principle of virtual works gives:

$$
\alpha=\frac{P x_{P}+V_{V} x_{V}+T y_{T}+F_{P} y_{F}-V_{H} y_{V}}{V_{V} y_{V}+P y_{P}}
$$

where $x_{P}$ affects the control displacement $d x_{P}$, i.e.:

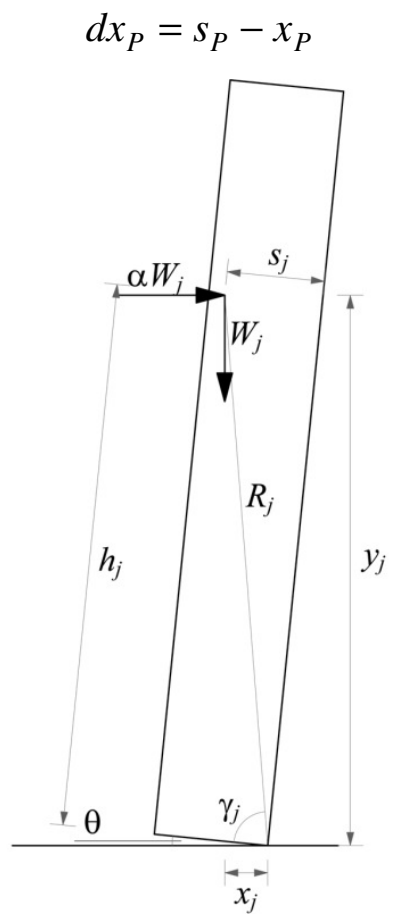

Figure 4: Varied kinematic configuration.

By assuming the reference values reported in Table 2, in the following subsections the role of each influencing parameter $\left(T, T_{V}, F_{P}\right)$ is highlighted with reference to the different loading conditions (Cases 1 and 2) and combinations a), b) and c). Considering the generic detached 
row $i$ in Fig. 5, the threshold displacement $d x_{P i}$ is reached when $d x_{i}=v$, i.e. when the overlapping of units is lost at the distance from the base equal to $\left(r_{i} h\right)$, being $r_{i}$ the number of rows still involved in frictional contact:

$$
r_{i}=n-i \quad i=0,2,4, \ldots, n
$$

\begin{tabular}{l|l|l|l}
\hline Parameter name & Variable & Definition & Reference value \\
\hline Tie-rods $(T)$ & $t$ & $T / P$ and $T_{V} / P$ & 0.3 \\
\hline Yielding & $t$ & $h / l$ & $1 / 3$ \\
\hline Frictional Resistance $\left(F_{P}\right)$ & $H / h$ & 40 \\
\hline Unit aspect ratio & $m$ & $f$ & 0.6 \\
Size ratio (n. of rows) & $n$ & $f$ & \\
Friction &
\end{tabular}

Table 2: Parameters for three-wall system sensitivity analysis.

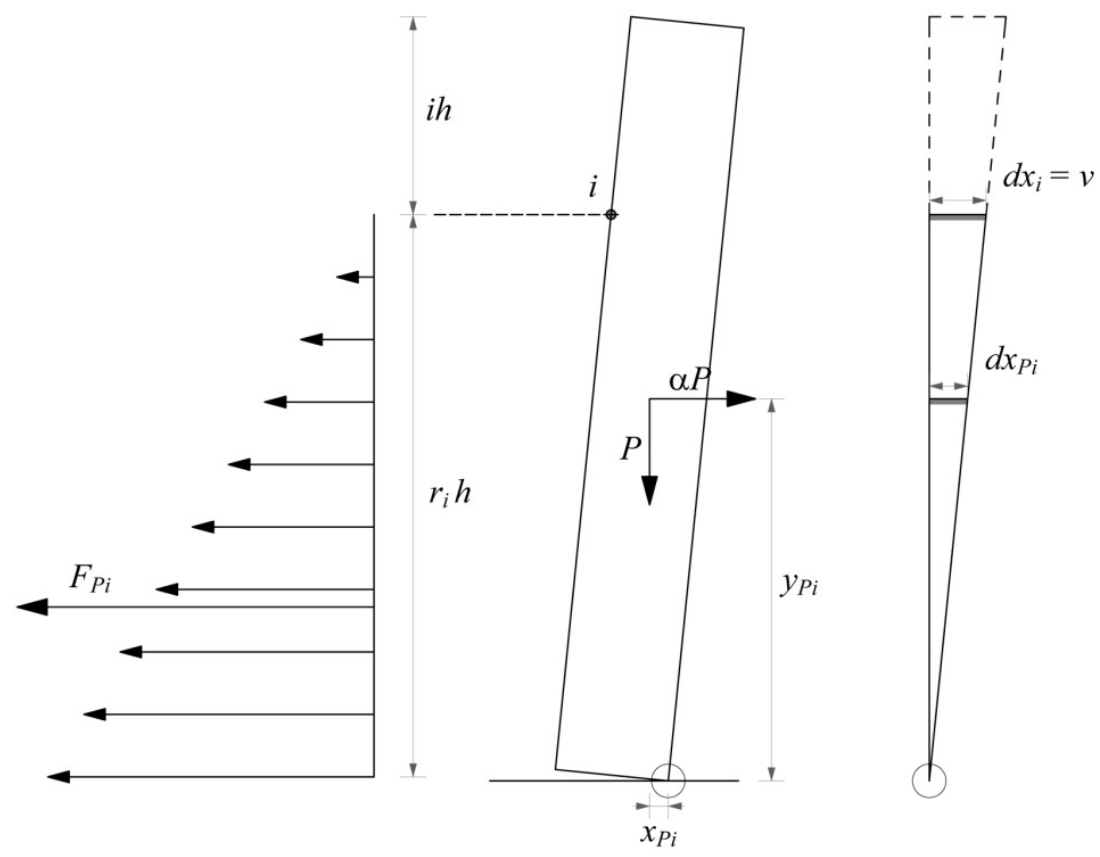

Figure 5: Variation of frictional resistances at increasing wall rotation.

Thus, it will be:

$$
d x_{P i}=\frac{n v}{2 r_{i}}
$$

while the corresponding reduced frictional resistance $F_{P i}$ can easily be calculated by Eq. (1), while replacing $n$ with $r_{i}$, i.e.:

$$
F_{P i}=\gamma \operatorname{shl} \frac{r_{i}\left(r_{i}+1\right)}{2} f
$$

The variation of the involved forces and the corresponding threshold displacements $d x$, along with the dimensionless performance levels of the system $\left(d x_{P} / s_{P}\right)$ are summarized in Table 3 and recalled in turn within the following subsections. 


\begin{tabular}{|c|c|c|c|}
\hline Involved forces & $\begin{array}{l}\text { Reference value } \\
\text { Force } / P(\%)\end{array}$ & $\begin{array}{l}\text { Threshold displace- } \\
\text { ment } \\
d x\end{array}$ & $\begin{array}{l}\text { Performance level } \\
d x_{P} / s_{P}(\%)\end{array}$ \\
\hline \multicolumn{4}{|l|}{ Constant forces } \\
\hline$P$ & 100 & $s_{P}$ & 100 \\
\hline$T$ & 30 & $d x: \varepsilon_{\mathrm{u}}=1 \%-4.5 \%$ & $10-45$ \\
\hline$T_{V}$ & 30 & $d x: \varepsilon_{\mathrm{u}}=1 \%-4.5 \%$ & $14-63$ \\
\hline$V_{V}$ & 36 & $s / 4$ & 35 \\
\hline$V_{H}$ & 20 & $s / 4$ & 35 \\
\hline \multicolumn{4}{|l|}{ Variable forces } \\
\hline$T_{10 \%}$ & 3 to 30 & $1 / 100 s: \varepsilon_{\mathrm{y}}=0.1 \%$ & 1 \\
\hline$F_{P i}$ & $F_{P i} / P($ Eq. $(8))$ & $v$ at $i$ & $d x_{P i} / s_{P}($ Eq. (7)) \\
\hline
\end{tabular}

Table 3: Variation of involved forces and performance levels of the system in large displacements.

\subsection{The Influence of the tie-rods on the displacement capacity}

The contribution of elasto-plastic tie-rods on the displacement capacity is analyzed in this section. As an assumption, the possibility of occurrence of flexural mechanisms is excluded.

In Fig. 6(a) the effect of tie-rods (10 s long) is represented through the comparison among the pushover curves for Cases $1 b$ ) and 2b), which, in turn, are also compared with the free wall condition (Case 1a)). In this figure the ultimate strain of tie-rods is assumed as $4.5 \%$.

In case of absence of floor structures (Case 1b)), $10 \%$ pretensioned horizontal tie-rods $\left(T_{10 \%}=3 \% P\right.$ in Table 3), give a stabilizing effect that increases the initial load factor of about $44 \%$ with respect to the free wall condition (Case 1a)). After rocking onset the pushover curve increases because the forces in tie-rods increase too (up to $30 \% P$ ) and at yielding the variation of the load factor is more than $270 \%$. The corresponding displacement of the control point is practically negligible $\left(1 \% s_{P}\right)$. A descending branch can then be observed, till tie-rods rupture which causes a sudden drop down of the static multiplier to the pushover curve of the wall without tie-rods. This can be identified as a displacement threshold $\left(45 \% s_{P}\right)$ and occurs when the ultimate strain of tie-rods is reached, here assumed as $4.5 \%$. As a realistic example, it is easy to verify these results for a wall thickness $s=0.6 \mathrm{~m}$ and yielding stress and diameter of two applied tie-rods equal to $205 \mathrm{~N} / \mathrm{mm}^{2}$ and $16 \mathrm{~mm}$, respectively.

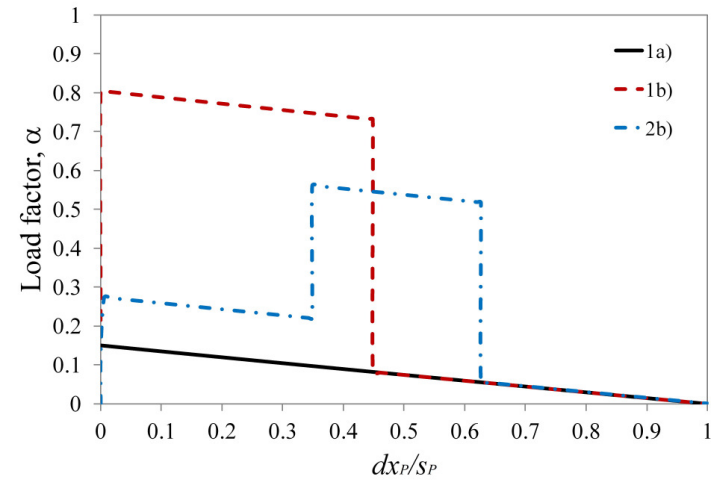

(a)

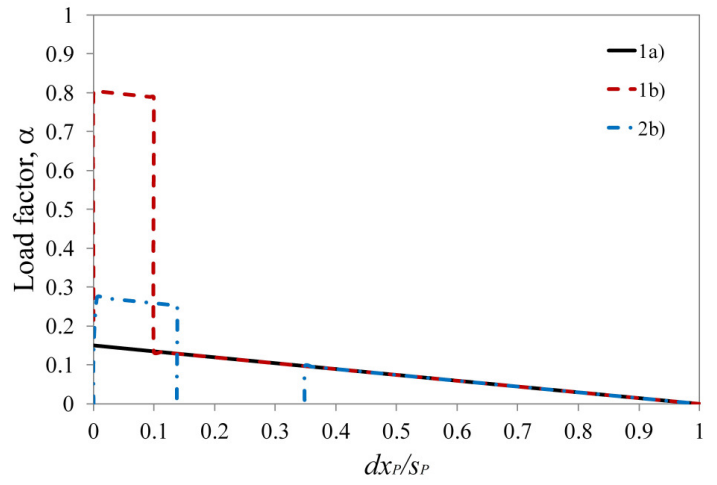

(b)

Figure 6: Influence of the tie-rods after the hinge formation. Pushover curves with ultimate strain of tie-rods of (a) $4.5 \%$ and (b) $1 \%$.

Regarding the Case 2b), due to the destabilizing effect of the vault, the activation static multiplier has a negative value close to zero, as it can easily been computed. After rocking 
onset the pushover curve increases because the forces in tie-rods increase too, till yielding, reaching a percentage increment of about $82 \%$ with respect to Case 1a). The pushover curve continues with a first descending branch until the displacement threshold of the control point due to the loss of effectiveness of the vault (involving its collapse), herein assumed as about $35 \%$ of half the wall thickness (Table 3). At this point the pushover curve sudden rises up as the tie-rods still are effective till their rupture. It is worth noting that the different position of the tie-rods in Case 2 implies a lower effect on the load multiplier but a greater displacement capacity with respect to the other case $\left(d x_{P} / s_{P}=63 \%\right.$ corresponding to $T_{V}$ in Table 3$)$.

A further investigation is carried out on the variation of the pushover curves in case of less ductile tie-rods, e.g. assuming their ultimate strain as 1\% (Fig. 6(b) and Table 3). As expected, the first branches of all curves are the same but descending for shorter increments of the displacements with respect to the previous analysis (Fig. 6(a)). In particular, the most relevant difference can be recognized in the case of presence of a vaulted structure (Case 2b)). In fact, since the displacement threshold of the tie-rods is lower than that corresponding to the vault, the rupture of the elasto-plastic elements, occurring at about $14 \%$ of half the wall thickness (Table 3), is coincident with the ultimate condition of the whole system, hence considered its displacement capacity.

\subsection{The Influence of the frictional resistances on the displacement capacity}

A far as the influence of frictional resistances is concerned, in Fig. 7 the effect of the interlocking between orthogonal walls is reported, with reference to the considered loading conditions and different unit aspect ratios (parameter $m$ ). The activation load factors for Cases 1c), and 2c) are relatively greater than those for Cases 1a) and 2a), whatever the unit aspect ratio. In particular, for $m=1 / 3$, all the activation load factors are greater than those for the free wall (Case 1a)), up to about $328 \%$ for Case 1c) (Fig. 7(a)). The subsequent linear descending branch of all curves is characterized by the effectiveness of frictional resistances acting on the whole height of the corners, till when these values start to reduce in correspondence with the first threshold displacement given by Eq. (7) with $i=2$.

The subsequent non-linear reduction of frictional forces represented by Eq. (8) implies a linear descending step function of $\alpha$, whose curve fitting can be represented by a parabolic curve. It is interesting to note in Fig. 7 that, especially for smaller unit aspect ratios $(m=0.2)$, the increasing displacement of the control point involves longer descending branches and shorter heights of the steps on the pushover curves. These two trends are due to the more displacement capacity associated with the lower part of the corners with respect to the upper one and lower frictional resistances, respectively.

Another threshold displacement characterized by sharp rising up of the curves can be observed for Case 2c) when the destabilizing effect of the overload is lost, i.e. for the loss of effectiveness of the vault (Table 3).

However, the most interesting remark is that the dimensionless control displacement, for which $\alpha=0$, is greater than unity whatever the case considered, unlike the external strengthening device represented by tie-rods. This can be better observed in Fig. 7(b) related to more slender units. It is evident that the activation load factors are improved significantly together with the pushover curves $\left(\alpha=0.06\right.$ at $\left.d x_{P} / s_{P}=1\right)$ and this means that walls composed by slender units in the vertical plane present a greater stabilizing contribution to the onset and displacement capacity of such out-of-plane failure mechanisms due to the fact that units with small $m$ ratios exhibit enlarged interlocking between them. 


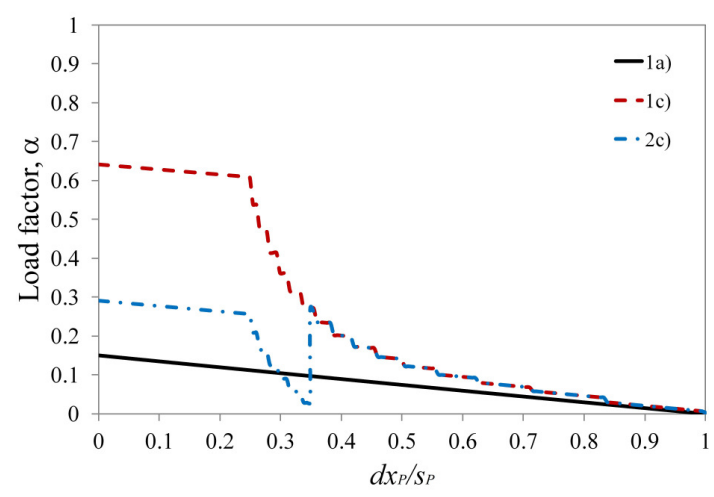

(a)

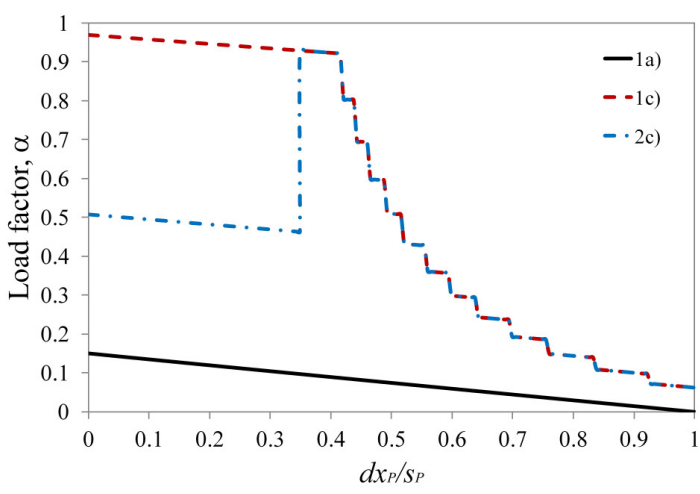

(b)

Figure 7: Influence of the frictional resistance due to interlocking between orthogonal walls after the hinge formation. Pushover curves with unit aspect ratio $m$ of (a) $1 / 3$ and (b) 0.2 .

\section{CONCLUSIONS}

Frictional resistances due to the interlocking between walls play an important role on the seismic assessment of the local out-of-plane mechanisms in existing masonry buildings, even more than other intrinsic or extrinsic loading and displacement capacities.

From the analytical point of view, a rigid-perfectly plastic model with dry contact interfaces governed by Coulomb failure criterion was assumed for masonry walls with regular units and staggering. The failure mode of the three-wall system was identified a priori, by considering two vertical cogged cracks along the corners, where frictional resistances can take place. The role of interlocking between orthogonal walls was particularly highlighted in comparison with another system of strength in masonry buildings, such as the effect of tie-rods.

Provided that other possible failure modes cannot occur, e.g. bond failure at the interface between the steel profile and the parental material or punching/compressive failure of masonry, the contribution of such an external strengthening device after the hinge formation was lower than that offered by friction. Also, it is worth noting that the detrimental effect of the static trust of a vaulted structure on the façade wall without strengthening could imply very low or even negative load factors if other existing stabilizing effects are neglected within the modeling approach. This interesting remark confirms the importance to consider other intrinsic capacities naturally exerted by the wall system, such as frictional resistances.

\section{ACKNOWLEDGEMENTS}

The authors acknowledge the sponsorship of the Italian Civil Protection, through the RELUIS Project - Line: Masonry Structures (2017).

\section{REFERENCES}

[1] C. Casapulla, A. Maione, L.U. Argiento, Seismic analysis of an existing masonry building according to the multi-level approach of the Italian Guidelines on Cultural Heritage. Ingegneria Sismica, 1, 2017, 1-21.

[2] A. Kooharian, Limit analysis of voussoir (segmental) and concrete arches. Journal of the American Concrete Institute, 24(4), 317-328, 1952. 
[3] D.C. Drucker, Coulomb friction, plasticity and limit loads. Journal of Applied Mechanics, 21(1), 71-74, 1954.

[4] J. Heyman, The stone skeleton. International Journal of Solids and Structures, 2, 249279, 1966.

[5] R.K. Livesley, A computational model for the limit analysis of three-dimensional masonry structures. Meccanica, 27(3), 161-172, 1992.

[6] C. Casapulla, Dry rigid block masonry: safe solutions in presence of Coulomb friction. Advances in Architecture Series, 7, 251-261, 2001.

[7] A. Orduña, Seismic assessment of ancient masonry structures by rigid blocks limit analysis. PhD Thesis, University of Minho, Guimarães, Portugal, 2003.

[8] C. Casapulla, Lower and upper bounds in closed form for out-of-plane strength of masonry structures with frictional resistances. D. D'Ayala, E. Fodde eds. $6^{\text {th }}$ International Conference on Structural Analysis of Historical Constructions (SAHC08), Bath, UK, vol. 2, July 2-4, 2008.

[9] T. Tran-Cao, Collapse analysis of block structures in frictional contact. $\mathrm{PhD}$ thesis, The University of New South Wales, Sydney, Australia, 2009.

[10] G. Milani, M. Pizzolato, A. Tralli, Simple numerical model with second order effect for the out-of-plane loaded masonry walls. Engineering Structures, 48, 98-120, 2013.

[11] P.B. Lourenço, Masonry modeling. M. Beer, I.A. Kougioumtzoglou, E. Patelli, S.-K. Au eds. Encyclopedia of Earthquake Engineering, Reference work, 1-13, 2014.

[12] C. Casapulla, F. Portioli, Experimental tests on the limit states of dry-jointed tuff blocks. Materials and Structures, 49(3), 751-767, 2016.

[13] C, Casapulla, A. Maione, Formulating the torsion strength of dry-stacked stone blocks by comparing convex and concave contact formulations and experimental results. Indian Journal of Science and Technology, 9(46), 107346, 2016.

[14] C. Casapulla, L.U. Argiento, C. Ceraldi, Experimental validation of in-plane frictional resistances in dry block masonry walls. $6^{\text {th }}$ International Conference on Computational Methods in Structural Dynamics and Earthquake Engineering, Rhodes Island, Greece, June 15-17, 2017.

[15] L. Giresini, Energy-based method for identifying vulnerable macro-elements in historic masonry churches. Bulletin of Earthquake Engineering, 44(13), 919-942, 2015.

[16] L. Giresini, M. Sassu, Horizontally restrained rocking blocks: evaluation of the role of boundary conditions with static and dynamic approaches. Bulletin of Earthquake Engineering, 15(1), 385-410, 2016.

[17] L. Giresini, M. Fragiacomo, M. Sassu, Rocking analysis of masonry walls interacting with roofs. Engineering Structures, 116, 107-120, 2016.

[18] C. Casapulla, P. Jossa, A. Maione, Rocking motion of a masonry rigid block under seismic actions: A new strategy based on the progressive correction of the resonance response. Ingegneria Sismica, 27(4), 35-48, 2010.

[19] C. Casapulla, On the resonance conditions of rigid rocking blocks. International Journal of Engineering and Technology, 7(2), 760-761, 2015. 
[20] C. Casapulla, A. Maione, Free damped vibrations of rocking rigid blocks as uniformly accelerated motions. International Journal of Structural Stability and Dynamics, DOI: http://dx.doi.org/10.1142/S0219455417500584, 2016.

[21] C. Casapulla, P. Jossa, A. Maione, A simplified procedure for the seismic safety of large and slender rigid masonry blocks. International Journal of Earthquake and Impact Engineering, 1(4), 333-359, 2016.

[22] C. Casapulla, A. Maione, Critical response of free-standing rocking blocks to the intense phase of an earthquake. International Review of Civil Engineering, 8(1), 1-10, 2017.

[23] C. Casapulla, A. Maione, Rocking resonance conditions of large and slender rigid blocks under the intense phase of an earthquake. $6^{\text {th }}$ International Conference on Computational Methods in Structural Dynamics and Earthquake Engineering, Rhodes Island, Greece, June 15-17, 2017.

[24] K. Doherty, M.C. Griffith, N.T.K. Lam, J.L. Wilson, Displacement-based analysis for out-of-plane bending of seismically loaded unreinforced masonry walls. Earthquake Engineering and Structural Dynamics, 31(4), 833-850, 2002.

[25] D. D'Ayala, Force and displacement based vulnerability assessment for traditional buildings. Bulletin of Earthquake Engineering, 3, 235-265, 2005.

[26] C. Casapulla, A. Maione, Out-of-plane local mechanisms in masonry buildings. The role of the orientation of horizontal floor diaphragms. J. Ingham, M. Dhanasekar, M. Masia eds. $9^{\text {th }}$ Australasian Masonry Conference, Queenstown, New Zealand, February 15-18, 2011.

[27] C. Casapulla, L.U. Argiento, The comparative role of friction in local out-of-plane mechanisms of masonry buildings. Pushover analysis and experimental investigation. Engineering Structures, 126, 158-173, 2016.

[28] C. Casapulla, L.U. Argiento, In-plane frictional resistances in dry block masonry walls and rocking-sliding failure modes revisited and experimentally validated, Composites Part $B$, under review.

[29] S. Lagomarsino, Seismic assessment of rocking masonry structures. Bulletin of Earthquake Engineering, 13, 97-128, 2015. 